\title{
AS VIVÊNCIAS DO CANDOMBLÉ NA POESIA ANCESTRAL DE OLIVEIRA SILVEIRA
}

\author{
Manoela Fernanda Silva de MATOS ${ }^{1}$
}

RESUMO: O presente artigo visa discutir a produção literária do poeta afro-gaúcho Oliveira Silveira, na análise de seus poemas será focado os seguintes temas: religião afro-brasileira (batuque afro-riograndense), memória e ancestralidade. Portanto, querer-se-á comprovar que os poemas de Oliveira Silveira buscam visibilizar sua afro-brasilidade, bem como, o local de pertencimento dos afrodescendentes no Brasil e a afirmação afrodescendente no cenário literário. Para tal discussão será utilizados arcabouços teóricos-crítico no que tange a literatura afro-brasileira e a teoria literária. Concluirse-á que Oliveira Silveira poeta negro, busca rememorar sua ancestralidade africana perdida, a Mãe África e a religião afro-brasileira como aporte para sua criação poética.

Palavras-chave: Literatura. Religião afro-brasileira. Afrodescendência. Memória.

\begin{abstract}
This paper aims to discuss the literary production of the afro-gaúcho poet Oliveira Silveira, the analyses of his poems will be focused on the following issues: afro-brazilian religion (batuque afrograndense), memory and ancestry. Therefore, it will want to prove that Oliveira poems aims to demonstrate his afro-brazilianism, as the place where afro-descendants belong in Brazil and the affirmation of African descent in the literary scene. To make such discussion, it will be used critic and theoretical frameworks regarding afro-brazilian literature and literary theory. It will be concluded that Oliveira Silveira a negro poet, attempts to recall his lost african ancestry showing to the further afrodescendants the history of their heros, search remembering his lost African ancestry, Mother Africa and african-Brazilian religion as a support for his poetic creation.
\end{abstract}

Keywords: Literature. Afro-Brazilian religion. Afrodescendant. Memory. 


\section{Introdução}

Às vezes te sinto como avó, Outras vezes te sinto como mãe.

Quando te sinto como neto

Me sinto como sou.

Quando te sinto como filho

Não estou me sentindo bem eu,

Estou me sentindo aquele

Que me arrancaram de dentro de ti. (À África, Oliveira Silveira- 1981).

Durante muito tempo as manifestações religiosas de matriz africana foram cerceadas do convívio social, sendo assim, o povo-de-santo é hostilizado e a religião afro-brasileira é vista como diabólica, como feitiçaria entre outros termos pejorativos que são usados para achincalhar a religião afro-brasileira. Este estigma é carregado pela religião afro-brasileira desde o tempo da escravidão, em que as manifestações religiosas de matriz africana eram consideradas pagãs e os negros eram proibidos de praticar sua religião, fato este que até hoje acontece, mas de forma diferente, principalmente com o avanço neopentecostal que está travando um sério embate com a religião afro-brasileira, surgindo assim, a intolerância religiosa que advém desde as investidas Católicas, deste modo:

[...] Foram perseguidas pela igreja Católica ao longo de quatro séculos, pelo Estado republicano, sobretudo na primeira metade do século XX, quando este se valeu de órgãos de repressão policial e de serviços de controle social e higiene mental, e, finalmente, pelas elites sociais num misto de desprezo e fascínio pelo exotismo que sempre esteve associado às manifestações culturais dos africanos e seus descendentes no Brasil. [...] (GONÇALVES, 2007, p. 23).

A intolerância e o preconceito religioso tem como base o não conhecimento, ou seja, não conhecer determinada religião, como funciona suas condutas, como é estabelecida a organização social, como são feitos os rituais e quais suas finalidades, é o que acontece com as religiões afro-brasileiras, como o Candomblé e a Umbanda. Antes de emitir uma opinião e/ou crítica sobre determinado assunto, é preciso estudar, conhecer, pois além das questões religiosas há também a questão cultural que está intimamente ligada com a religião, mas principalmente com identidade de um grupo, neste caso, os negros, pois a religião afro-brasileira pode ser considerada o local de pertencimento e de identidade dos sujeitos afrodescendentes. 
Diante das várias manifestações de intolerância religiosa assistida pela sociedade, como invasões a terreiros, violência contra o povo-de-santo, quebra dos símbolos afro-brasileiros, tornam-se necessárias leis que protegem todo e qualquer tipo de manifestação religiosa. No entanto, a liberdade religiosa vem sendo questionada, pois todos os cultos são respeitados, mas quando se trata das religiões afro-brasileiras o embate é violento, principalmente por parte dos neopentecostais que sempre atacam a religião, demonizando os orixás e a prática dos cultos afro-brasileiros.

É sabido que a religião afro-brasileira está inserida na sociedade desde o tempo da escravidão, no entanto, passou grande parte da história do Brasil, marginalizada e fora do centro urbano das grandes cidades, bem como não possuíam o status de religião. Entretanto, com o advento das manifestações culturais de origem africana, a religião afro-brasileira passou a ser reconhecida, assim há uma "recuperação" da cultura africana em solo brasileiro, pois a religião afro-brasileira faz parte da cultura africana, e é pela religião que são passados os ensinamentos milenares do povo africano.

Perceber as manifestações culturais africanas foi de fundamental importância para a atual situação do Brasil, que "com a liberdade religiosa, o pluralismo religioso avançou consideravelmente - ajudando, inclusive a ampliar e defender a própria liberdade -, assim como o trânsito religioso". (MARIANO, 2007, p.128). Apesar dessa liberdade religiosa e deste avanço em relação aos séculos passados, há um longo caminho a ser percorrido, pois ainda se tem a sombra da intolerância religiosa que paira sobre a religião afro-brasileira.

Contudo, a religião afro-brasileira adquire novos adeptos e simpatizantes religiosos, bem como estudos acadêmicos que trabalham as relações sociais dentro dos terreiros, os desdobramentos teórico-simbólicos e a importância da religião para a identidade dos sujeitos negros. Outro fator que contribuiu com a religião afro-brasileira foi à literatura afro-brasileira, pois a religião afro-brasileira faz parte da construção poética e da narrativa afrodescendente.

Em um primeiro momento a Literatura Afro-brasileira surge como uma forma de denúncia dos "prejuízos" adquiridos com o regime escravocrata. Em seguida, efetivouse como uma literatura propriamente dita, com características e público próprios, contribuindo para o reconhecimento da cultura afro-brasileira por toda sociedade.

Segundo Nazareth Fonseca ${ }^{2}$, a Literatura Afro-brasileira possui duas vertentes: a primeira pretende interferir na dinâmica social nas quais os afrodescendentes estão expostos, logo, esta produção literária tem um texto engajado em questões políticas e o 
escritor assume-se como negro e sabe seu lugar de pertencimento. Já a segunda vertente denúncia os preconceitos sofridos pelos afrodescendentes, mas tem por objetivo reconstituir, dentro da literatura um "novo" espaço para os afrodescendentes, também traz as vozes recolhidas dos escravos, ou seja, sua ancestralidade. Portanto, a literatura afro-brasileira é a voz que representa a coletividade afrodescendente, que por muito tempo ficou calada e sem visibilidade e só teve abertura através mundo das letras, onde se conta as agruras sofridas pelos negros, mas também glorifica a cultura africana e afro-brasileira.

A religião afro-brasileira possui símbolos e significados específicos para o povode-santo, e é neste sentido que se observa a importância da literatura afro-brasileira, pois esta desmitifica vários mitos que são inerentes a cultura africana e afro-brasileira, por exemplo, o mito do surgimento do universo e dos homens segundo as crenças africanas, as histórias dos orixás, portanto, a literatura afro-brasileira reconta a história africana e afro-brasileira, glorifica os heróis negros, mostra a importância da cultura africana na formação da identidade dos sujeitos afrodescendentes.

É neste momento que o poeta afro-gaúcho como gosta de ser chamado, Oliveira Silveira (1941-2009), apresenta a religião afro-brasileira, mas de maneira inversa ao que se conhece, ou seja, Oliveira Silveira ressignifica a religião afro-brasileira e mostra a religião de dentro, isto é sob o olhar do praticante. Oliveira Silveira nasceu no estado do Rio Grande do Sul, e a manifestação religiosa africana que se tem lá é o Batuque ${ }^{3}, \operatorname{logo}$, possui diferenças do candomblé de São Paulo e de outros estados. Tendo características próprias, como por exemplo, no nome dos orixás, nos cultos, nas oferendas, etc.

A religião afro-brasileira apresentada por Oliveira Silveira é mágica e misteriosa. O poeta faz releitura de tempos de glórias, mostra os orixás em sua totalidade com erros e acertos assim como os humanos, mas de maneira sublime. $\mathrm{O}$ candomblé nas poesias de Oliveira não é apenas religião, mas sim um modo de ser e viver na religião afro-brasileira, assim a poética silveriana adquire um status de ensinamento da cultura e história africana e afro-brasileira.

\section{Memória: A busca por uma Ancestralidade Afrodescendente}

A memória está muito presente na literatura de um modo geral, no entanto, se faz fundamental na construção literária afro-brasileira, reconta a história dos africanos trazidos para o Brasil, assim como reconta a história dos heróis negros do Brasil e do mundo, e principalmente os ensinamentos e tradições ancestrais. 
A memória está intimamente ligada com a Literatura, com o contexto de produção em que a obra literária foi produzida, portanto a memória é um processo cultural coletivo, ou seja, a memória é uma produção coletiva de um determinado grupo social que viera a ser marginalizado pela sociedade.

Unindo os relatos dos ex-exilados e as lembranças dos velhos operários existe a mesma preocupação pelos grupos que são marginalizados pela história oficial. Se não em engano, é pela via da marginalização que se propaga e frutifica a fórmula do relato autobiográfico, ou memorialista (numa visão não conservadora), nos anos subsequentes ao retorno dos exilados. Só que o fenômeno da marginalização é compreendido como uma espécie de exílio interno: trata-se de determinados grupos sociais que eram e são desprovidos de voz dentro da sociedade brasileira, cuja voz era e é abafada. (SANTIAGO, 2002, p.40).

A literatura afro-brasileira busca afirmar a ancestralidade afrodescendente no Brasil, como, na religião, na comida, nas festas, nas músicas, etc. Logo,

[...] da memória coletiva de um determinado grupo, uma memória estruturada com suas hierarquias e classificações, uma memória também que, ao definir o que é comum a um grupo e o que, o diferencia dos outros, fundamenta e reforça os sentimentos de pertencimento e as fronteiras socioculturais. (POLLAK, 1989, p.01).

Os grupos sociais marginalizados têm na literatura uma forma de escapismo e de denúncia, mas também, um relato autobiográfico de suas condições sociais. Há também os lapsos de memória, isto é, o esquecimento do seu passado, do seu lugar de pertencimento, conta uma lenda africana que os negros africanos trazidos para serem escravos no Brasil, tinham que dar sete voltas na chamada árvore do esquecimento, pois, está árvore recolhia todo o passado destes futuros escravos e toda sua vida seria "apagada", para que não tivessem passado e nem futuro na nova terra, seriam seres vazios, sem alma, ocos.

Deste modo, a Literatura afro-brasileira recolhe em si vozes que durante séculos ficaram caladas e/ou adormecidas, portanto, a Literatura afro-brasileira é o modo de ser e estar dos afrodescendentes que se embeberam das fontes de África e sua população milenar para produzir seus escritos.

Oliveira Silveira poeta afro-gaúcho bebeu dessa fonte e pode transmitir os saberes ancestrais africanos e, mais tarde, afro-brasileiros em suas poesias, que são compostas de uma lírica, de uma escrita própria que a cada verso vai ganhando literariedade, na qual envolve o leitor e o faz transcender para outros universos nunca antes percorridos. Octavio Paz no seu renomado livro O arco e a lira (1982) tem uma definição muito poética e descritiva, se assim pode se dizer, sobre poesia (poesis) que reflete muito bem a poética mágica e envolvente de Oliveira Silveira. 
A poesia é conhecimento, salvação, poder, abandono. Operação capaz de transformar o mundo, a atividade poética é revolucionária por natureza; exercício espiritual é um método de libertação interior. A poesia revela este mundo; cria outro. Pão dos eleitos; alimento maldito. Isola; une. Convite à viagem; regresso à terra natal. Inspiração, respiração, exercício muscular. Súplica ao vazio, diálogo com a ausência, é alimentada pelo tédio, pela angústia e pelo desespero. Oração, litania, epifania, presença. Exorcismo, conjuro, magia. Sublimação, compensação, condensação do inconsciente. Expressão histórica de raças, nações, classes. Nega a história: em seu seio resolvem-se todos os conflitos objetivos e o homem adquire, afinal, a consciência de ser algo mais que passagem. (PAZ, 1982, p.15).

Oliveira Silveira faz uso da memória afrodescendente para compor sua poética, na qual possui características e significados próprios, peculiares e intrínsecos para a literatura afro-brasileira. No poema $O$ Ancestral (1981), que diz:

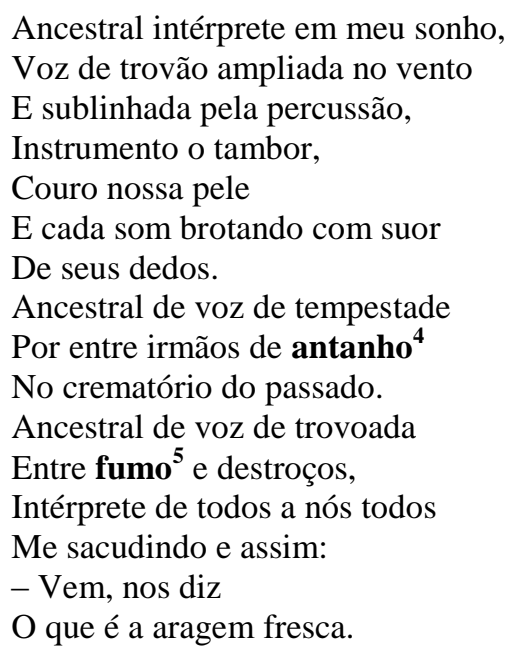

No poema o eu-enunciador ${ }^{6}$ tem um reencontro com o passado para compor o seu presente para se autoafirmar como agente de sua vida, como intérprete da sua situação atual, na qual seu ancestral vem em sonho para resgatá-lo de uma possível inércia.

Podemos ler nas entrelinhas as presenças dos orixás Xangô e Iansã que tem como elementos naturais o trovão e o vento, respectivamente. Portanto, a presença desses elementos demonstra a busca do eu-enunciador por sua ancestralidade africana e sua ligação com o candomblé.

A presença do instrumento musical, o tambor, que é muito usado nos ritos religiosos afro-brasileiros, nos remete a musicalidade que é fundamental na Literatura afro-brasileira, pois a língua africana é muito musicada, logo a poesia carrega essas características. Podemos perceber uma leve rima nos versos 4 e 5 (tambor/suor). Que dá um caráter ainda mais literal para a poesia. 
No seguinte verso "por entre irmãos de antanho, no crematório do passado". A palavra antanho muito bem colocada no poema nos remete a ancestralidade perdida, ao antigo, logo, vemos a busca do eu-enunciador por seu passado, por sua árvore genealógica. Mas também quer se renegar o passado dolorido e sofrido dos seus antepassados escravos, numa busca constante por uma nova vida, por seu "novo" lugar de pertencimento. A palavra "crematório" agrega a simbologia do fogo, que é o elemento natural dominado pelo orixá Ogum, que também domina as guerras, pode ser que esse orixá guiasse os escravos nas guerras contras os senhores-brancos. O fogo também pode ser o símbolo do poder, pois somente o animal homem pode "domina-lo". O fogo pode nos remeter ao Ser Supremo. Portanto, a simbologia do fogo vai depender do ponto de vista e da crença do leitor.

No poema pode-se observar o que Zilá Bernd chama de reterritorialização

[...] o fazer poético passa a ser equivalente a um processo de reterritorialização, ou seja, a uma tentativa de recomposição de um sistema próprio de representações. O poema tem, portanto, sua gênese no desejo de reparar sucessivas perdas como a da memória da ancestralidade africana, da ação heroica nos quilombos, enfim da própria história. (BERND, 1988, p. 23).

O poema Haiti (1981) retrata a luta do país na conquista por sua independência que tem como principal líder o negro Toussaint-Louverture, na qual obteve a tão sonhada liberdade política, é preciso salientar que o Haiti foi o primeiro país a ser liberto por mãos negras. É um poema que glorifica os feitos haitianos, mas também lança luz para as revoluções que ocorrem em todo mundo.

A epígrafe no poema é do poeta negro Aimé Césaire que juntamente com os poetas Leon Damas e Leopold Senghor fundaram o Manifesto à Negritude, que foi fundamental para a "entrada" da cultura africana nas Américas e na Europa. Assim diz o poema:

Grande teu passado,

Célebre na história

E que alto teu grito liberto

Até hoje movendo nossos braços

Num gesto altivo de lança em riste!

Haiti,

Sagrado no culto vodu,

Heróico em Dessalines,

Soberbo em Toussaint- Louverture,

"o primeiro dos negros", Haiti!

Haiti,

Meu verso quisera ser

Ponta de lança e guizo de serpente

Para expressar-te a ti! 
A ancestralidade no poema se faz presente pelo rememoramento do euenunciador que enaltece os heróis do Haiti Jean-Jacques Dessalines e ToussaintLouverture que foram os principais idealizadores da Revolução Haitiana, que pregava a liberdade dos haitianos que viviam sobre as amarras dos colonizadores franceses.

O vodu (Sévis Gine) religião tipicamente haitiana teve papel fundamental na luta pela liberdade, pois conta à lenda que a primeira pratica do vodu foi à cerimônia chamada de Bwa Kayaman ou Bois Caeman em 1791, nesta cerimônia o espírito de Ezili Dantor (antepassado de uma família antiga do Haiti chamada Dantor que é cultuado no vodu) possuía uma pessoa e falava para eles sobre a independência haitiana, logo, todas as pessoas que ali estavam se comprometeram com a luta pela liberdade e este comprometimento resultou no primeiro estado negro independente.

É importante salientar que o vodu é uma religião que mistura ritos do catolicismo, do espiritismo e indígena, cultuando os antepassados e entidades que são conhecidas como loas, algumas de suas características se confundem com o candomblé. O eu-enunciador glorifica a religião haitiana para demarcar o local de pertencimento de seus heróis e suas forças vitais (axé) que são providas da religião e manejam de maneira mágica a vitória dos haitianos contra os franceses.

A gramática do poema é fundamental para a leitura, por exemplo, o ponto de exclamação no final de cada estrofe para reforçar a glória dos heróis e a altivez do poema. As disposições das consoantes e vogais no poema causam sonoridade e criam uma pausa imagética entre um verso e outro.

A história do Haiti é importante na formação da identidade afrodescendente em todo mundo, por isso o eu-enunciador faz uso de palavras fortes que possam expressar a grandiosidade deste país, que ainda sofre com a pobreza exacerbada e desastres naturais que afetam sua população, mas o axé deste povo fará com que eles possam reconstruir seu país e cantar as glórias dos seus antepassados. O que reforça a última estrofe "Haiti,/ meu verso quisera ser/ ponta de lança e guizo de serpente/ para expressar-te a ti!”.

A ponta de lança e o guizo de serpente representam a força desse grupo, que ao se juntar fazem um barulho tão grande que acabam por assustar seu predador, neste caso os colonizadores, que vieram para retirar a cultura haitiana e impor a cultura dos homens brancos e ocidentais.

Esse verso representa a importância desse país para formação dos negros e apresenta a força negra unida em busca da liberdade, quando mobilizados se caminha 
para junto para uma mesma direção, a fim de alcançar os objetivos e amenizar as desigualdades sociais e raciais no Brasil.

A literatura afro-brasileira rememora os heróis negros que ao longo da história mundial foram apagados pelo processo de embranquecimento ao qual não só os negros foram expostos, mas também os brancos que não conseguirem ver a importância do negro para a construção da sociedade brasileira, desde modo, a literatura afro-brasileira busca "contemplar o resgate da história do povo negro da diáspora brasileira, passando pela denuncia da escravidão e de suas consequências ou ir até à glorificação de heróis como Zumbi e Ganga Zumba." (ASSIS DUARTE) ${ }^{7}$.

\section{A Religião Afro-brasileira: Por uma Afirmação Afrodescendente em Oliveira Silveira}

Durante muito tempo as religiões de matriz africana foram consideradas demoníacas, por grande parte dos cristãos (católicos e evangélicos), que por não entenderem os ritos e simbologias dos cultos afrodescendentes classifica-os pejorativamente. A religião foi uma forma de resistência que os negros escravizados encontraram para manterem-se próximos de suas origens que lhes foram arrancadas ao atravessar o Atlântico.

A religião afro-brasileira é feita pelo sincretismo religioso que é muito presente em todos os cultos religiosos do mundo, no entanto, algumas religiões insistem em apontar as demais e desqualificar certos rituais o que é inviável tendo em vista toda a mistura na qual foi submetida o Brasil, como se observa na ressignificação dos símbolos afro-brasileiros por parte das igrejas neopentecostais.

Para fugir das perseguições dos senhores, os escravos faziam suas rezas e sincretizavam os santos católicos com os orixás do Candomblé e assim podiam manter suas raízes. Este sincretismo origina o Candomblé afro-brasileiro, por exemplo, Oxalá (Candomblé) e Jesus Cristo (Catolicismo), pois ambos são "filhos do criador supremo e salvador dos homens na Terra." (SILVA, 2002, p. 80).

O que acontece com o Candomblé e o Catolicismo é o processo de transculturação e/ou antropofagia que faz com que dois cultos opostos se aglutinem e formem uma nova "religião" se assim pode se dizer. Perceber que um culto está dentro do outro é mais fácil para banir a intolerância religiosa que assola ainda e muito as outras formas de cultuar Deus. 
O Candomblé é uma religião cheia de mistérios e regras, os membros do terreiro aprendem à língua dos escravos e a língua na qual o terreiro descende, por exemplo, de origem banta, jejê-nagô, etc. Aprendem a cozinhar a comida dos orixás, mas o principal ensinamento é o respeito pelos mais velhos e, sobretudo sobre sua ancestralidade. O Candomblé é um modo de vida, pois não há a dualidade entre bem x mal, céu x inferno, porque todos os seres humanos agregam essa dualidade, mas cada sujeito deve seguir seu caminho e saber fazer suas escolhas para que seu ori (cabeça) esteja bem e sempre ligado com o orixá que domina seu ori.

Religião é festa, santo é alegria, culto é prazer. Orixá precisa sempre de
atenção, comida, bebida, roupas e muitos objetos rituais, além de música e
dança. Não se pode imaginar candomblé sem festa, que não é qualquer festa,
mas a festa de um estilo, de um particular modo de ver o mundo sobrenatural
e o mundo dos humanos. Além disso, a concepção iorubana de pessoa, que se
mantém viva e fundamental nos candomblés do Brasil, ensina que antes
mesmo de se cultuar os deuses é preciso cultuar o próprio ego, a cabeça, o ori
do mortal devoto. (Reginaldo Prandi)

Oliveira Silveira cultua o Candomblé em seus poemas, glorifica a história dos heróis que foram esquecidos, mas principalmente enaltece a religião afro-brasileira, desmistificando mitos que circundam o candomblé, pois

Podemos entender por que é através do estudo de seus signos, formas e consumo de bens materiais e simbólicos que o candomblé pode ser entendido como um complexo cultural no qual se encontra um conjunto de valores que, uma vez inseridos num novo contexto, são reelaborados, dando origem a formas simbólicas específicas, através das quais os fiéis desenvolvem e transmitem seus conhecimentos e suas atitudes em relação à vida, delineando seu estilo de vida. (AMARAL, 2005, p.24-25).

No poema Oferenda, o eu-enunciador demonstra liricamente como é feita uma cerimônia de candomblé, assim diz o poema:

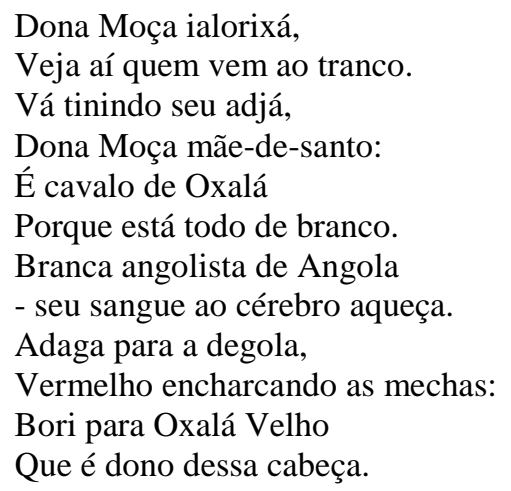

Pode-se notar o "passo-a-passo" de um ritual de candomblé, onde há o sacrifício de um animal para que ori do filho-de-santo seja energizado, ou seja, sua força vital continue e seu orixá esteja alimentado. 
O eu-enunciador apresenta a ialorixá, que significa mãe em iorubá que é a Dona Moça, esta é a pessoa mais importante do terreiro, na qual todos os filhos-de-santo se reportam a ela, somente a mãe-de-santo pode jogar os búzios e fazer a iniciação dos futuros filhos-de-santo. A mãe-de-santo carrega todos os orixás, no entanto, tem um orixá que predomina, pois este "acerta" o ori de seu filho, consagrando-o.

A mãe-de-santo carrega seu adjá, que são sinetas ritualísticas confeccionadas em latão ou zinco niquelado, é produzida para chamar os orixás". No quinto verso: "é cavalo de Oxalá/ porque está todo de branco". Cavalo no candomblé é o filho-de-santo que já está preparado para receber o seu orixá, ou seja, o orixá "monta" em seu filho para que ele possa se manifestar e a festa ou ritual possa ser conduzido. O branco é a cor de Oxalá, geralmente os rituais para Oxalá são feitos na sexta-feira, pois este é o seu dia. É interessante notar que o sacrifício animal ao longo de séculos vem ganhando características diferentes, pois alguns animais que eram sacrificados dantes hoje em dia não podem mais serem sacrificados, por causa das leis de proteção aos animais, portanto, tudo é passível de mudança até mesmo às religiões que precisam adaptar seus rituais para o tempo presente.

$\mathrm{Na}$ segunda estrofe, no verso primeiro: "branca angolista de Angola", pode-se perceber a origem do candomblé da mãe Dona Moça, portanto, seus rituais seguem o rito angola que segundo Vagner Gonçalves da Silva em seu livro Candomblé e Umbanda: caminhos da devoção brasileira (2005),

\footnotetext{
Esse rito, que abrange principalmente o cerimonial congo e cabinda, procura enfatizar a herança das religiões bantos. Essa nação, embora seja a mais popular e a mais praticada pelo povo-de-santo, é vista por membros de outras nações como deturpada, pois possui um panteão bem mais abrangente. Cultua, além dos inquices (deuses dos bantos), os orixás, os voduns, os vunjes (espíritos infantis) e os caboclos. (Silva, 2005 p. 66-67).
}

Logo, o candomblé é divido em nações, sendo que cada qual possui seus rituais seu panteão próprio. Havendo, portanto, um sincretismo religioso dentro das nações de candomblé segundo as descendências africanas das mães ou pais-de-santos dos terreiros.

A mãe-de-santo empunha sua adaga para degola de animal que pode ser um frango e seu sangue vai restaurar o axé (força vital) do orixá e seu filho. Esta força encontra-se presente em seres inanimados e nos animais. Bori ${ }^{10}$ é o rito de fortalecimento espiritual da cabeça (ori) de uma pessoa que é consagrado a um determinado orixá, neste caso é Oxalá. 
Além da "apresentação" do candomblé com seus mistérios e suas divindades, Oliveira utiliza de recursos linguísticos para compor sua poesia, como as rimas, a disposição das palavras no texto para criar sonoridade, o que é fundamental para a poesia afrodescendente. A simplicidade das palavras, não torna o poema simplista, mas com uma energia transcendental no uso das palavras de origem africana que são utilizados no candomblé, recuperando a ancestralidade africana do poeta e de seus leitores que se veem representados em cada verso, que veem sua ancestralidade e sua descendência ali expressa.

\section{Considerações finais}

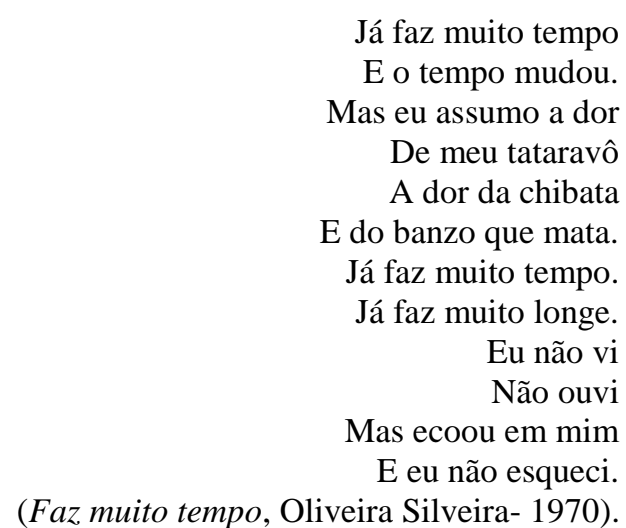

A poesia de Oliveira Silveira busca reafirmar a identidade afrodescendente com base na religião afro-brasileira, assim há um recontro com as raízes africanas, com a Mãe África que muitas vezes foi esquecida pela sociedade, mas que pela Literatura afrobrasileira foi revisitada e recontada sobre o viés de seus descendentes, como forma de afirmar e buscar a identidade negra perdida.

Ao reviver a história dos heróis pela poesia de Oliveira Silveira aprende-se o manejo das armas empunhadas pelos negros a fim de buscar a liberdade, mas também a luta desferida pelo mundo das letras, pela poesia que reconta a história sob a ótica dos escravizados, luta esta feita a base de muito sangue e por mãos pretas que reescrevem a história do Brasil e mostra quão importante é para o sujeito se identificar com sua descendência.

O Candomblé é a história do povo brasileiro, é a história daqueles que foram marginalizados e esquecidos durante muito tempo, é neste local que se pode rememorar os ancestrais com seus ensinamentos, enfim o Candomblé é o local de pertencimento do sujeito negro, a estrutura espiritual, o por vir e o devir. 
É por todas essas lutas que os afrodescendentes buscam cada vez mais, reverenciar a história e a cultura do povo negro, pela Literatura, que está agremiando espaço na mídia dando visibilidade ao povo negro e sua história. Portanto, a literatura é um dos caminhos para se conhecer a cultura afro-brasileira, que expressa todo o sofrimento dos negros escravos ou não, mas também toda a luta pela liberdade, pelos direitos cerceados, pela igualdade perante a sociedade, mas principalmente o respeito como qualquer outro cidadão, a fim de reconstruir e afirmar a identidade afrodescendente.

Que a história não negue as personalidades negras que contribuíram de maneira direta ou indireta para a construção do Brasil, que foi feita sobre sangue e açoite, sobre música e macumba. Reconhecer a história negra é se autorreconhecer.

\section{Referências Bibliográficas:}

BERND, Z. Introdução à literatura negra. São Paulo: Editora Brasiliense, 1988.

DAMASCENO, B. G. Poesia negra no modernismo brasileiro. Campinas: Pontes Editores, 1988.

DUARTE, E. de A. Literatura afro-brasileira. Disponível em: www.letras.ufmg.br/literafro. Acesso em: 22/dez/2011.

SOUZA, F.; LIMA, M. N. (Orgs.). Literatura afro-brasileira. Salvador: Centro de Estudos Afro-Orientais; Brasília: Fundação Cultural Palmares, 2006.

FONSECA, M. N. S. Poesia afro-brasileira - vertentes e feições. Disponível em: www.letras.ufmg.br/literafro. Acesso em: 02/jan/2012.

LOPES, N. Novo dicionário Banto do Brasil: contendo mais de 250 propostas etimológicas acolhidas pelo Dicionário Houaiss. Rio de Janeiro: Pallas, 2003.

MARIANO, R. Pentecostais em ação: a demonização dos cultos afro-brasileiros. In: Intolerância religiosa: Impactos do Neopentecostalismo no campo religiosa Afrobrasileiro. São Paulo: Editora da Universidade de São Paulo, 2007.

PAZ, O. O arco e a Lira. Trad. Olga Savary. Rio de Janeiro: Nova Fronteira, 1982.

PRANDI, R. As religiões afro-brasileiras e seus seguidores. Civitas- Revista de Ciências Sociais, v.3, nº 1, jun. 2003.

POLLAK, M. Memória, esquecimento e silêncio. Trad. Dora Rocha Flaksman. Rio de Janeiro, 1989.

SANTIAGO, S. Nas malhas da letra: ensaio. Rio de Janeiro: Rocco, 2002. 
SILVA, V. G. da. Candomblé e umbanda: caminhos da devoção brasileira. São Paulo: Selo Negro, 2005.

SILVA, V. G. da. Intolerância religiosa: Impactos do Neopentecostalismo no campo religiosa Afro-brasileiro. São Paulo: Editora da Universidade de São Paulo, 2007.

SILVEIRA, O. Roteiro dos Tantãs. Porto Alegre: Edição do Autor, 1981.

SILVEIRA, O. Antologia Poética de Oliveira Silveira. Porto Alegre: Evangraf, 2010.

\section{Notas:}

${ }^{1}$ Graduada em Letras Vernáculas e Clássicas pela Universidade Estadual de Londrina (UEL), Mestranda em Estudos Literários (UEL), Graduanda em Pedagogia (UEL), Tutora do Curso Pedagogia Oferta Especial (UEL), Aluna-colaboradora do Núcleo dos Estudos Afro-Asiáticos (UEL) e Revisora da Revista Estação Literária (UEL). E-mail: manoelafernanda_manu@ @otmail.com.

${ }^{2}$ Explicação retirada do artigo Poesia afro-brasileira - vertentes $e$ feições de Maria Nazareth Soares Fonseca, disponível em www.letras.ufmg.br/literafro.

${ }^{3}$ Usaremos candomblé no lugar de batuque para que o leitor possa compreender melhor o efeito da religião afro-brasileira, sem que eu precise fazer diferenciação técnica entre um e outra, levando em consideração que o principio religioso em ambas é praticamente o mesmo, o que irá diferenciar são as oferendas aos Orixás, pois o batuque é uma religião denominada afro-rio- grandense, portanto, seus seguidores levam em consideração seu local de pertencimento.

${ }^{4}$ Antanho: Antigamente.

${ }^{5}$ Fumo: Faixa de crepe para luto (BH)- O étimo consagrado é o mesmo de fumo, vapor pardacento. Mas não podemos desprezar o quicongo fumu, marca ou sinal de nascença sobre a pele. (Retirado do Novo dicionário Banto do Brasil de Nei Lopes).

${ }^{6} \mathrm{O}$ uso do eu-enunciador é segundo as concepções teóricas e críticas de Zilá Bernd em seu livro Introdução á literatura negra (1988) que afirma: "Esse eu lírico em busca de uma identidade negra instaura um novo discurso - uma semântica do protesto - ao inverter um esquema onde ele era o Outro: aquele de quem se condoíam ou a quem criticavam. Passando de outro a eu, o negro assume na poesia sua própria fala e conta a história de seu ponto de vista. Em outras palavras: esse $e u$ representa uma tentativa de dar voz ao marginal, de contrapor-se aos estereótipos (negativos e positivos) de uma literatura brasileira legitimada pelas instâncias de consagração."

7 Citação retirada do artigo Literatura afro-brasileira de Eduardo de Assis Duarte, disponível em: www.letras.ufmg.br/literafro.

${ }^{8}$ Citação retirada do prefácio do livro Xirê! O modo de crer e viver no candomblé de Rita Amaral, 2005.

9 Significado retirado do livro Candomblé e umbanda: caminhos da devoção brasileira de Vagner Gonçalves da Silva, 2005.

${ }^{10}$ Idem. 